\title{
Sex-steroid milieu determines diabetes rescue in pttg-null mice
}

\author{
M Fraenkel, J Caloyeras, S-G Ren and S Melmed
}

Cedars-Sinai Research Institute, David Geffen School of Medicine at UCLA, 8700 Beverly Blvd, Los Angeles, California 90048, USA

(Requests for offprints should be addressed to S Melmed, Academic Affairs, Room 2015, Cedars-Sinai Medical Center; Email: melmed@csmc.edu)

\begin{abstract}
Male mice that are pttg-null develop sexually dimorphic diabetes with hypoinsulinemia secondary to reduced postnatal $\beta$-cell proliferation and an inability to expand islet cell mass with aging. We therefore examined the effects of sex-steroid manipulation on diabetes development in pttg $^{-1-}$ male mice. Surgical gonadectomy was followed by implantation of 90-day slow-release pellets releasing $17 \beta$-estradiol $(0.36 \mathrm{mg} /$ pellet $)$, placebo or dihydrotestosterone (DHT; $12.5 \mathrm{mg} /$ pellet). Mean fasting blood sugars at the end of the study were $414 \pm 54 \mathrm{mg} / \mathrm{dl}$ for $\mathrm{pttg}^{-1-}$ controls and $371 \pm 14 \mathrm{mg} / \mathrm{dl}$ for $\mathrm{pttg}^{->-}$mice gonadectomized and treated with DHT compared with $124 \pm 40$ and $85 \pm 12 \mathrm{mg} / \mathrm{dl}$ in gonadectomized $\mathrm{pttg}^{-1-}$ males treated with placebo or estradiol, respectively $\left(P<0 \cdot 01\right.$ compared with control $\left.\mathrm{pttg}^{-/-}\right)$. Gonadectomy with and without estradiol treatment did not increase the very low circulating insulin levels in pttg-null males
\end{abstract}

(fasting insulin $0.44 \pm 0.04 \mathrm{ng} / \mathrm{ml}$ in $\mathrm{pttg}^{-/-}$controls, $0.47 \pm 0.07$ and $0.4 \mathrm{ng} / \mathrm{ml}$ in $\mathrm{pttg}^{-/}$gonadectomized males treated with placebo or estradiol, respectively). Gonadectomy increased serum adiponectin levels $\left(4.9 \pm 008 \mu \mathrm{g} / \mathrm{ml}\right.$ in $\mathrm{pttg}^{-/-}$controls versus $13 \pm 0.08$ and $7.5 \pm 0.6 \mu \mathrm{g} / \mathrm{ml}$ in $\mathrm{pttg}^{-1-}$ gonadectomized males treated with placebo or estradiol, respectively; $P<0 \cdot 001$ and $P<0 \cdot 05)$, accompanied by increased insulin sensitivity. The results show that gonadectomy delayed, and gonadectomy with additional estradiol treatment prevented, diabetes development in $\mathrm{pttg}^{-{ }^{-}}$males, possibly through increased insulin sensitivity mediated by elevated serum adiponectin levels. Male-selective effects of disrupted $\beta$-cell proliferation in the absence of pttg are restored by sex-steroid effects on peripheral insulin sensitivity.

Journal of Endocrinology (2006) 189, 519-528

\section{Introduction}

pttg is the functional mammalian homolog of yeast securin (Pei \& Melmed 1997, Zou et al. 1999), which facilitates sister-chromatid separation during the mitotic transition from metaphase to anaphase (Pei \& Melmed 1997). pttg-null male mice develop hyperglycemia secondary to hypoinsulinemia starting at 6 months of age (Wang et al. 2003). By 1 year, $>80 \%$ of male pttg $^{-\prime-}$ mice are diabetic with hypoinsulinemia secondary to reduced post-natal $\beta$-cell proliferation and an inability to expand islet cell mass with aging. Diabetes onset is accompanied by loss of fat tissue. In contrast, $\mathrm{pttg}^{-1-}$ female mice rarely develop diabetes before 1 year of age and the incidence of diabetes in older pttg-null females (more than 1 year) is increased. Moreover, ovariectomy causes earlier onset of diabetes at 6 months of age in female pttg $^{-/-}$mice (Wang et al. 2003).

Several animal models exhibit sexually dimorphic diabetic phenotypes (Rossini et al. 1978, Paik et al. 1982, Kava et al. 1989, Leiter 1989, Efrat 1991, Shi et al. 1994, Kim et al. 2001, Thomas et al. 2001, Weksler-Zangen et al . 2001, Geisler et al. 2002, Li et al. 2003, Iglesias et al. 2004). In some, male gonadectomy had no effect, or accentuated the diabetic phenotype (Leiter 1981, 1989, Leiter et al.
1989, Efrat 1991, Kava et al. 1992), while in others gonadectomy protected against development of diabetes (Rossini et al. 1978, Maclaren et al. 1980, Kava et al. 1992, Shi et al. 1994, Weksler-Zangen et al. 2001). Removal of testosterone from the sex-steroid milieu of the male animal improved insulin sensitivity in most studies, and thus was protective against development of hyperglycemia. The protective role of estrogen in the pathogenesis of diabetes has also been demonstrated. Estrogen positively affects insulin sensitivity and increases insulin production (Bailey \& Ahmed-Sorour 1980), and ovariectomy of animals with a genetic predisposition to develop diabetes triggered diabetes onset in some female animals (Puah \& Bailey 1985, Efrat 1991, Shi et al. 1994). Moreover, animals in which estrogen receptor $\alpha$ or the aromatase genes have been disrupted have increased insulin resistance and impaired glucose tolerance (Heine et al. 2000, Jones et al. 2000).

To elucidate the role of sex steroids in the pathogenesis of diabetes in pttg-null animals, males were surgically gonadectomized at the age of 4 weeks and implanted with 90-day slow-release pellets releasing $17 \beta$-estradiol, placebo or dihydrotestosterone (DHT). Fasting blood glucose levels were monitored, and glucose- and 
insulin-tolerance tests were preformed to assess the effects of these manipulations on diabetes development in this model.

\section{Materials and Methods}

\section{Animals}

pttg $^{-1-}$ mice (Wang et al. 2001) were kept in a hybrid background derived from C57/BL6 and $129 \mathrm{SvJ}$ mouse strains. Animals were housed with a 12-h light:12-h darkness cycle and fed standard chow ad libitum. Experiments were approved by the Institutional Animal Care and Use Committee of Cedars-Sinai Research Institute, Los Angeles, CA, USA.

Four-week-old male $\mathrm{pttg}^{+/+}$and $\mathrm{pttg}^{-/-}$mice were surgically gonadectomized (or sham operated) under isoflurane anesthesia and implanted every 90 days with estradiol $(0.36 \mathrm{mg} / \mathrm{pellet}$; Innovative Research of America, Sarasota, FL, USA) or placebo (Saba et al. 2002, van Eickels et al. 2003). Controls included $\mathrm{pttg}^{+/+}$and pttg $^{-/-}$males with no intervention, or gonadectomized and treated with DHT $(12.5 \mathrm{mg} /$ pellet; same time points as other pellets).

\section{Blood assays}

Fasting blood glucose was measured twice a month starting at 4 weeks of age from tail blood samples after an overnight fast, using OneTouch Ultra glucometer (Lifescan; Johnson and Johnson, Milpitas, CA, USA). Animals with blood-glucose measurements above $150 \mathrm{mg} / \mathrm{dl}$ were considered as having diabetes.

Blood collected from the tail vein after an overnight fast was allowed to clot and then separated by ultracentrifugation. The following serum analytes were measured: insulin concentrations were measured in samples collected during glucose loading using an ultra-sensitive rat ELISA kit (CrystalChem, Downers Grove, IL, USA); fasting concentrations of adiponectin were measured using a mouse adiponectin RIA kit (Linco Research, St Charles, MO, USA); and C-peptide levels were measured by RIA using a rat C-peptide RIA kit (Linco Research).

Leptin and insulin were measured using the Lincoplex Adipokine panel (Linco Diagnostics, St Charles, MO, USA). Estradiol levels were measured by RIA using a 3rd Generation Estradiol RIA kit (Diagnostic Systems Laboratories, Webster, TX, USA).

\section{Intraperitoneal insulin and glucose-tolerance test}

For glucose-tolerance testing (GTT), mice were fasted $16 \mathrm{~h}$ before i.p. glucose injection $(1 \mathrm{~g} / \mathrm{kg}$ body weight $)$ and tail-vein blood collected at the indicated times. For insulin-tolerance testing (ITT), mice were fasted $6 \mathrm{~h}$ before i.p. insulin injection (1 unit/kg body weight), and glucose measured at specific time points.

\section{Histological, immunohistological and morphometric analysis}

Pancreata were isolated immediately after $\mathrm{CO}_{2}$ euthanasia and fixed overnight at $4{ }^{\circ} \mathrm{C}$ in $10 \%$ buffered formalin, followed by processing and paraffin embedding. Blocks were sectioned $(3-5 \mu \mathrm{M})$ and stained with hematoxylin and eosin. For immunostaining following antigen retrieval with citrate buffer, guinea-pig anti-insulin and rabbit anti-glucagon (both from Dako-cytomation, Carpinteria, CA, USA) were used. Primary antibodies were visualized using rhodamine-conjugated goat anti-guinea-pig antibody (Jackson ImmonoResearch, West Grove, PA, USA) and fluorescein-conjugated goat anti-rabbit antibody (Molecular Probes, Eugene, OR, USA) using an Olympus fluorescence microscope and digital camera. For morphometric analysis, $1 \times$ images of the hematoxylin and eosin sections were used to calculate pancreatic surface area using ImageJ software (National Institutes of Health, Bethesda, MD, USA). Consecutive sections from the same block were immunostained for insulin and glucagon. Using ImageJ software the numbers of islets (defined as a minimum of five insulin-positive cells) in the same section were counted and the surface area of insulin-positive and glucagon-positive cells measured and averaged for all islets in the section. $\beta$-Cell area in the section was calculated by summating the individual insulin-positive cells area expressed as a percentage of the total pancreatic area observed.

\section{Statistical analysis}

Insulin resistance was assessed by the homeostasis model assessment-insulin resistance (HOMA-IR) index (Matthews et al. 1985), which was calculated as [fasting blood glucose $(\mathrm{mg} / \mathrm{dl}) \times$ fasting insulin $(\mathrm{mg} / \mathrm{ml})] / 405$ (Umeda et al. 2003).

Statistical comparisons were performed using the one tailed unpaired t-test with Welch's correction, unless otherwise stated. One-way ANOVA was used when appropriate and is stated in the text. Data were analyzed using Prism software (Prism 4; Graphpad Software Inc, San Diego, CA, USA). Data in graphs are depicted as means \pm S.E.M. Circulating leptin concentrations were log-transformed to normalize the distribution.

\section{Results}

Diabetes is prevented in gonadectomized $\mathrm{pttg}^{-1-}$ males treated with estradiol, and delayed in gonadectomized $\mathrm{pttg}^{-1-}$ males

Eighty percent of sham-operated males and all males with no intervention (control) $\mathrm{pttg}^{-/-}$mice developed 

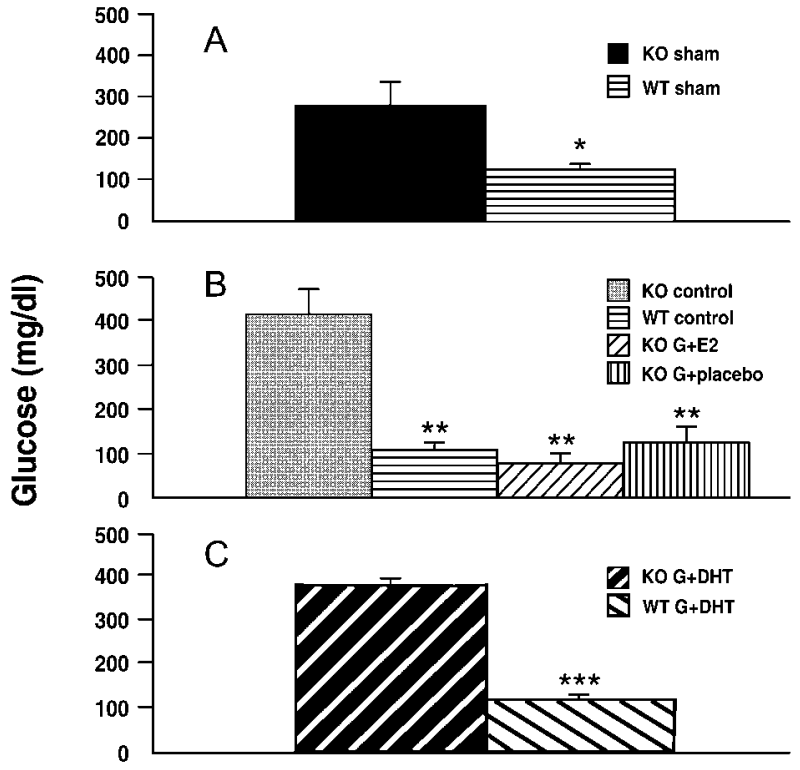

Figure 1 Fasting blood glucose in $\mathrm{pttg}^{-/-}(\mathrm{KO})$ and $\mathrm{pttg}^{+/+}(\mathrm{WT})$ male mice after sex-steroid manipulation. (A) Fasting blood glucose in 10-month-old sham-operated $\mathrm{pttg}^{-1-}$ (mean $276 \pm 57 \mathrm{mg} / \mathrm{dl})$ and $p t t^{+/+}(123 \pm 7 \mathrm{mg} / \mathrm{dl})$ males; ${ }^{*} P<0 \cdot 05$. (B) Fasting blood glucose in 10-month-old male $\mathrm{pttg}^{-1-}$ controls $(414 \pm 54 \mathrm{mg} / \mathrm{dl})$ and male $\mathrm{ptg}^{+/+}$controls $(104 \pm 7 \mathrm{mg} / \mathrm{dl})$, 13-month-old pttg $^{-1-}$ gonadectomized males treated with estradiol (KO G+E2; $85 \pm 12 \mathrm{mg} / \mathrm{dl})$ and gonadectomized $\mathrm{pttg}^{-/-}$males treated with placebo (KO G+placebo;

$124 \pm 40 \mathrm{mg} / \mathrm{dl}$ ); ${ }^{* *} P<0.01$ compared with pttg $^{-/-}$control males. (C) Fasting blood glucose in 9-month-old gonadectomized $\mathrm{pttg}^{-/-}(\mathrm{KO} \mathrm{G}+\mathrm{DHT} ; 371 \pm 14 \mathrm{mg} / \mathrm{dl})$ and $\mathrm{pttg}^{+/+}(\mathrm{WT} \mathrm{G}+\mathrm{DHT}$; $108 \pm 16 \mathrm{mg} / \mathrm{dl})$ males treated with $\mathrm{DHT} ;{ }^{* * *} P<0 \cdot 001$.

hyperglycemia by 10 months (mean fasting blood glucose: sham $\mathrm{pttg}^{-/-} \quad 276 \pm 57 \mathrm{mg} / \mathrm{dl}$ versus $\mathrm{pttg}^{+/+}$ $115 \pm 28 \mathrm{mg} / \mathrm{dl}$, and control $\mathrm{pttg}^{-/-} 414 \pm 54 \mathrm{mg} / \mathrm{dl}$ versus $\mathrm{pttg}^{+/+} 104 \pm 7 \mathrm{mg} / \mathrm{dl} ; \quad P<0 \cdot 05$ and $P<0 \cdot 01$ respectively, $n=4-5$ animals per group; Fig. 1).

Gonadectomized $\mathrm{pttg}^{-1-}$ males treated with estradiol $(n=4)$ had normal fasting blood glucose levels for up to 13 months (mean fasting blood glucose: $85 \pm 12 \mathrm{mg} / \mathrm{dl}$ compared with control $\mathrm{pttg}^{-1-}$ males at 10 months of age; $P<0 \cdot 01$; Fig. 1B). Mean serum estradiol levels in treated $\mathrm{pttg}^{-1-}$ and $\mathrm{pttg}^{+/+}$mice were higher than in control pttg $^{-1-}$ mice $(253 \pm 97,230 \pm 56$ and $13 \pm 1 \mathrm{pg} / \mathrm{ml}$ respectively; $P<0 \cdot 01$ by one-way ANOVA with Kruskal-Wallis test). GTT $(1 \mathrm{~g}$ glucose $/ \mathrm{kg}$ body weight) was performed serially on mice gonadectomized and treated with estradiol $(n=4)$ at 3, 6, 9 and 12 months, and these values remained normal (data not shown).

Gonadectomized $\mathrm{pttg}^{-/-}$male mice treated with placebo $(n=5)$ were protected from developing diabetes mellitus (mean fasting blood glucose at 13 months: $124 \pm 40 \mathrm{mg} / \mathrm{dl}$ versus pttg $^{-1-}$ controls $414 \pm 54 \mathrm{mg} / \mathrm{dl}$; $P<0 \cdot 01$; Fig. 1B), while a single gonadectomized pttg $^{-1-}$ male developed overt fasting hyperglycemia

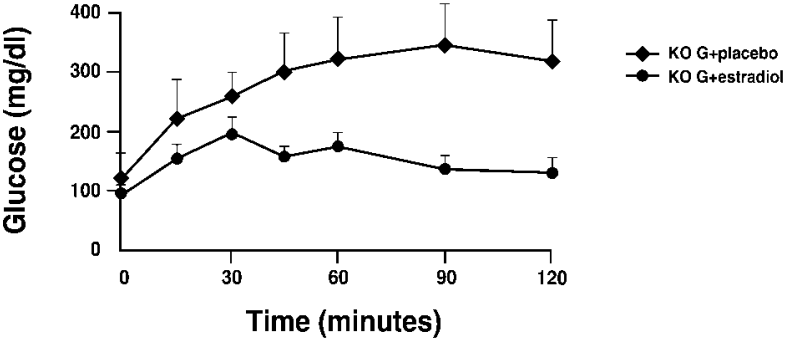

Figure 2 GTT in 12-month-old $\mathrm{pttg}^{-/-}(\mathrm{KO})$ and $\mathrm{pttg}^{+/+}(\mathrm{WT})$ male mice after sex-steroid manipulation. Glucose $(1 \mathrm{~g} / \mathrm{kg}$ body weight) was injected intraperitoneally and blood glucose measured after 15, 30, 45, 60, 90 and $120 \mathrm{~min}$. Glucose values are from GTT of gonadectomized $p t t{ }^{-/-}$males treated with estradiol (KO $\mathrm{G}+$ estradiol) and placebo (KO G+placebo); $n=4-5$ in each group.

$(260-370 \mathrm{mg} / \mathrm{dl})$. By 12 months, gonadectomized pttg $^{-1-}$ males treated with placebo were glucoseintolerant compared with gonadectomized males with additional estradiol treatment. The mean area under the curve of GTT values was lower in gonadectomized $\mathrm{pttg}^{-1-}$ animals treated with estradiol when compared with gonadectomy alone $(18 \cdot 5 \pm 2 \cdot 3$ versus $35 \cdot 2 \pm 7 \cdot 4$ arbitrary units; $P<0 \cdot 05$; Fig. 2$)$.

Gonadectomized pttg $^{-9}$ male mice treated with DHT $(n=4)$ developed diabetes as expected (mean fasting blood glucose at 9 months: $371 \pm 14$ versus $108 \pm 16 \mathrm{mg} / \mathrm{dl}$ in $\mathrm{pttg}^{+/+}$similarly treated animals; $n=5$ $P<0 \cdot 001$; Fig. 1C), and were also glucose intolerant, similar to control $\mathrm{pttg}^{-1-}$ males.

Diabetes onset was accompanied by weight loss in pttg $^{-1-}$ male controls and in sham-operated and gonadectomized animals with supplemental DHT. pttg $^{-1-}$ gonadectomized males with and without estradiol treatment had lower body weights at an early age, irrespective of diabetes onset, when compared with $\mathrm{pttg}^{-}{ }^{-}$and pttg $^{+/+}$control mice (data not shown).

Gonadectomy with or without additional estradiol therapy fails to elicit fasting and post-challenge insulin responses in $\mathrm{pttg}^{-1-}$ males

Insulin levels were measured to determine whether the observed protection from diabetes conferred by sexsteroid manipulation was due to increased circulating insulin concentrations. Fasting serum insulin levels in control $\mathrm{ptgg}^{+/+}$males rose gradually with age with no similar increase noted in $\mathrm{pttg}^{-1-}$ males $(1.95 \pm 0.6$ versus $0 \cdot 44 \pm 0.04 \mathrm{ng} / \mathrm{ml}$ at 10 months; $P<0 \cdot 05$; Fig. $3 \mathrm{~A})$. Interestingly, although gonadectomized $\mathrm{pttg}^{->-}$males treated with estradiol were protected from developing hyperglycemia, they did not exhibit increased fasting insulin levels (Fig. 3A). Measurement of C-peptide levels in the same animals confirmed this observation (data not shown). Eight-month-old gonadectomized pttg $^{-1-}$ males had 


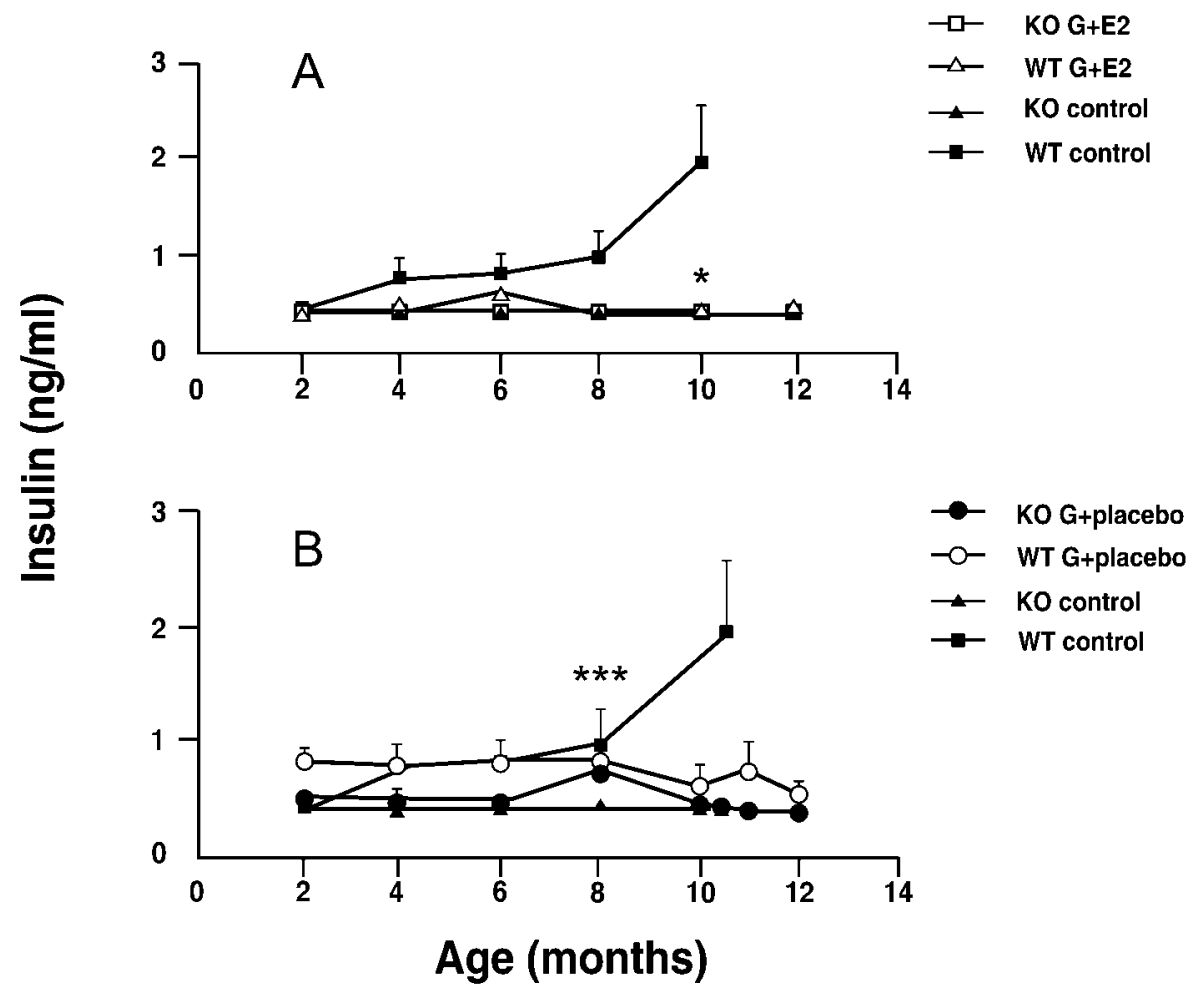

Figure 3 Fasting serum insulin levels in $\mathrm{pttg}^{-/-}(\mathrm{KO})$ and $\mathrm{pttg}^{+/+}(\mathrm{WT})$ male mice after sex-steroid manipulation, measured at 2, 4, 6, 8 and 10 months. (A) pttg ${ }^{-1-}$ control males (KO control; $\mathbf{\Delta}$ ), $\mathrm{pttg}^{+/+}$control males (WT control; $\left.\mathbf{\square}\right)$, gonadectomized $\mathrm{pttg}^{-/-}$males treated with estradiol (KO $\mathrm{G}+\mathrm{E} 2 ; \square$ ) and gonadectomized $\mathrm{pttg}^{+/+}$males treated with estradiol (WT G+E2; $\triangle$ ); ${ }^{\star} P<0 \cdot 05$ for

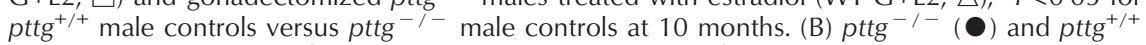
$(\bigcirc)$ male controls, $\operatorname{ptg}^{-/-}(\boldsymbol{\Delta})$ and gonadectomized $\mathrm{pttg}^{+/+}(\boldsymbol{\square})$ males treated with placebo; $* * * P<0.001$ for gonadectomized $p t t g{ }^{-1-}$ males treated with placebo versus $p^{-1 g^{-1-}}$ control males at 8 months.

modestly increased fasting insulin levels compared with control $\mathrm{pttg}^{-1-}$ animals $(0.734 \pm 0.06$ versus $0 \cdot 43 \pm 0.03 \mathrm{ng} / \mathrm{ml} ; \quad P<0 \cdot 001$ by one-way ANOVA; Fig. 3B), an increase that was not evident at other experimental time points and was not confirmed by C-peptide levels. Most circulating fasting insulin measurements in pttg $^{-1-}$ control males were below the detection sensitivity of the Lincoplex kit. It is therefore possible that insulin levels in gonadectomized $\mathrm{pttg}^{-/-}$males exceeded those of controls, but the assay was not sufficiently sensitive to detect differences. Thus it remains unclear as to whether gonadectomy alone resulted in unambiguously elevated insulin levels in $\mathrm{pttg}^{-1-}$ males. Serial insulin levels in gonadectomized pttg $^{-/-}$and pttg $^{+/+}$males treated with DHT were in accord with those of control animals (data not shown).

The appropriate wild-type insulin response to a glucose challenge (GTT) was markedly attenuated in pttg $^{-1-}$ males (for the 0,30, 60 min time points $(P<0 \cdot 05)$ and for the $120 \mathrm{~min}$ time point $(P<0 \cdot 02)$; Fig. 4A). Moreover, gonadectomy of $\mathrm{pttg}^{-/-}$males with or without estradiol treatment did not normalize insulin levels following a glucose challenge, compared with age-matched control pttg $^{-1-}$ males $(0,30,60$ and $120 \mathrm{~min}$ time points; $P>0.05$; Fig. 4). Gonadectomized pttg $^{-1-}$ males treated with DHT also failed to raise insulin levels following a glucose load when compared with $\mathrm{pttg}^{+/+}$mice that exhibited a normal response to glucose (data not shown).

These results indicate that gonadectomy, followed by additional estradiol or no added treatment, protected male $\mathrm{pttg}^{-{ }^{-}}$mice from developing diabetes in both the fasted and the post-glucose-challenged state without appreciably increasing insulin levels.

Increased insulin sensitivity accompanied by elevated serum adiponectin and leptin levels in gonadectomized $\mathrm{pttg}^{-1-}$ males

To assess whether diabetes rescue occurred as a result of increased insulin sensitivity, ITTs were preformed on mice aged $8-11$ months ( $n=3$ animals per group). Control $\mathrm{pttg}^{+/+}$and $\mathrm{pttg}^{-1-}$ males were assessed at 8 months 

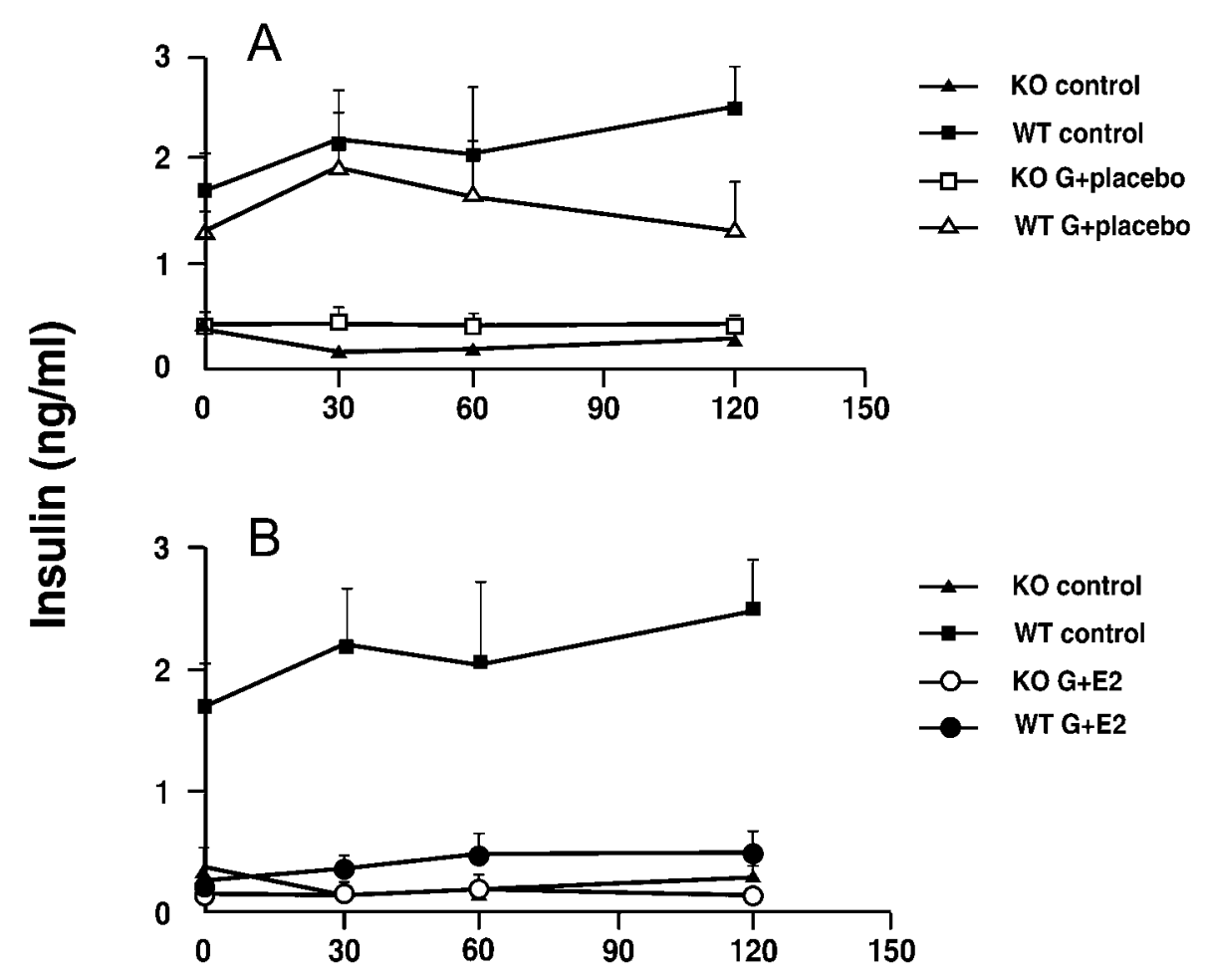

Time (minutes)

Figure 4 Insulin levels during GTT of 9-month-old male $\mathrm{pttg}^{-/-}(\mathrm{KO})$ and $\mathrm{pttg}^{+/+}$(WT) mice after sex-steroid manipulation. Blood was collected for insulin measurement at baseline $(0)$ and after 30, 60 and 120 min during IPGTT. (A) pttg ${ }^{-/-}$controls ( $\mathbf{\Delta}$ ) failed to elicit a normal insulin response when compared with $\mathrm{pttg}^{+/+}$controls $(\mathbf{\square})$ for the 0,30 and 60 min time points $(P<0 \cdot 05)$ and at $120 \mathrm{~min}(P<0 \cdot 02)$. Gonadectomy $\left(\mathrm{pttg}^{-/-}, \square ; \mathrm{pttg}^{+/+}, \triangle\right)$ did not rescue insulin production during

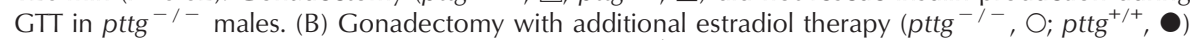
did not rescue insulin production during GTT in $p_{t t g}{ }^{-1}$ males $(n=3-5$ in each group).

(mean fasting glucose: $107 \pm 21$ and $204 \pm 81 \mathrm{mg} / \mathrm{dl}$ respectively), gonadectomized $\mathrm{pttg}^{+/+}$and $\mathrm{pttg}^{-1-}$ males treated with DHT at 9 months (mean fasting glucose: $108 \pm 16$ and $371 \pm 14 \mathrm{mg} / \mathrm{dl}$ respectively), and gonadectomized $\mathrm{pttg}^{+/+}$and $\mathrm{pttg}^{-}{ }^{-}$males treated with placebo or estradiol were assessed at 10 and 11 months respectively (all were normoglycemic).

A modest increase in insulin sensitivity was observed in gonadectomized pttg $^{+/+}$and pttg $^{-/-}$males both with and without estradiol treatment. The time required to attenuate basal glucose levels by $50 \%$ was $\sim 60 \mathrm{~min}$ in control $\mathrm{pttg}^{-1-}$ males versus 30 and $40 \mathrm{~min}$ for gonadectomized $\mathrm{pttg}^{-1-}$ males receiving placebo or estradiol respectively. Gonadectomized $\mathrm{pttg}^{-}{ }^{-}$males treated with DHT did not improve insulin sensitivity.

The HOMA-IR (Homeostasis Model Assessment) index (Matthews et al. 1985, Umeda et al. 2003), a physiologic marker for insulin resistance, was calculated for each group of animals at 2 month intervals starting at the age of 2 months. A higher HOMA index score is an estimated reflection of increased insulin resistance. Gonadectomized $\mathrm{pttg}^{-{ }^{-}}$males with and without added estradiol treatment had a lower HOMA index at 10 months when compared with control pttg $^{-1-}$ and $\mathrm{pttg}^{+/+}$males, indicating that gonadectomy with or without estradiol treatment likely enhanced insulin sensitivity $\left(0.096 \pm 0.02\right.$ in gonadectomized pttg $^{-1-}$ males treated with placebo, $0 \cdot 108 \pm 0.18$ in gonadectomized $\mathrm{pttg}^{-/-}$ males treated with estradiol and $0.368 \pm 0.08$ in control $\mathrm{pttg}^{-1-} ; P<0.025$ comparing $\mathrm{pttg}^{-1-}$ gonadectomized with and without additional estradiol with control pttg $\left.^{-} /^{-}\right)$. These observations were confirmed by correlating fasting glucose and insulin levels (data not shown). $\mathrm{pttg}^{+/+}$animals have low glucose levels in the face of high insulin levels, while pttg $^{-}{ }^{-}$animals have high glucose levels in the face of low insulin levels. Gonadectomy with and without additional estradiol treatment resulted in changing $\mathrm{pttg}^{-/-}$mice to the area on the correlation plot associated with low insulin and low glucose levels, thus implying increased insulin sensitivity. 

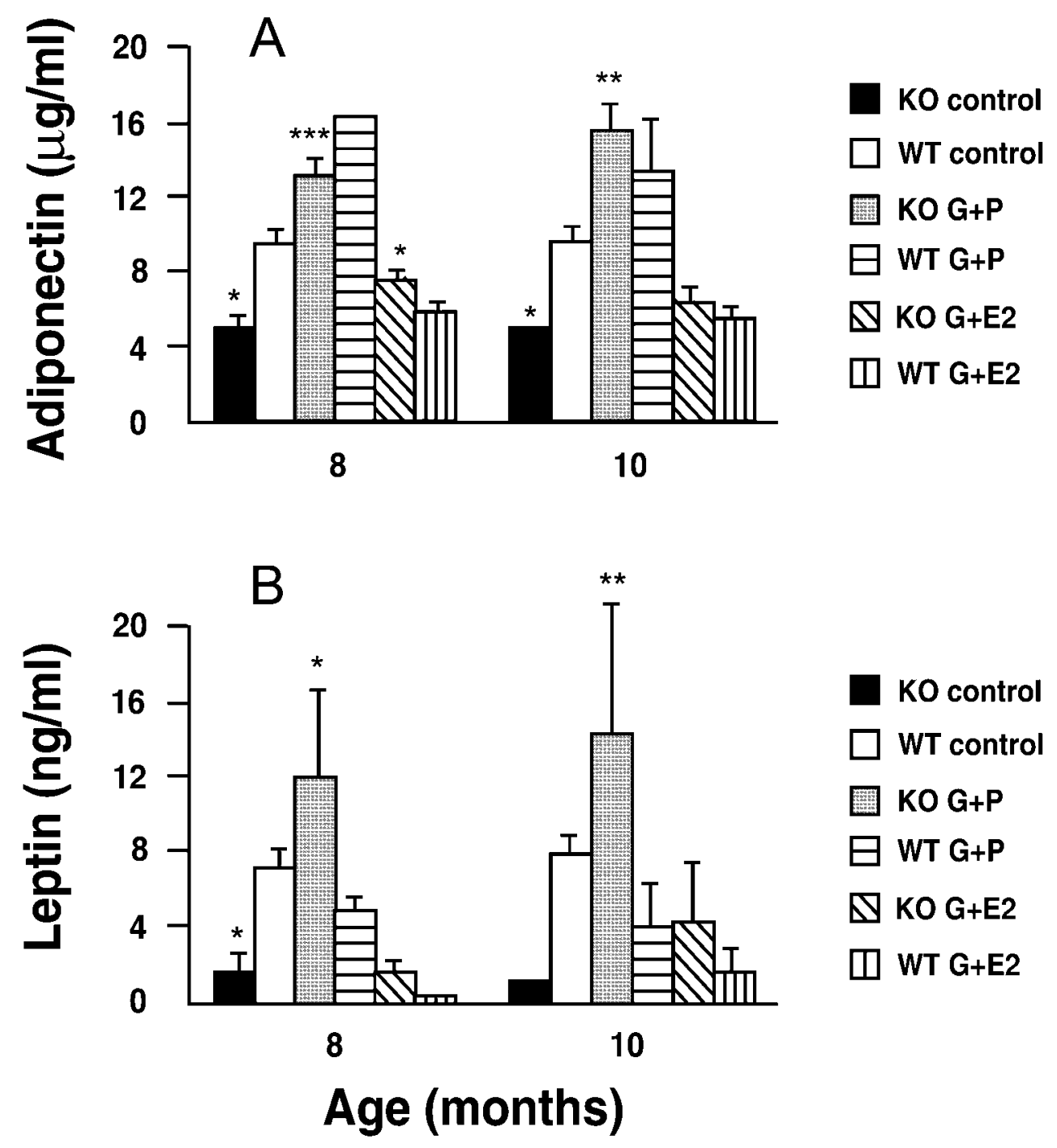

\begin{abstract}
Figure 5 Serum adipokine levels in male $\mathrm{pttg}^{-/-}(\mathrm{KO})$ and $\mathrm{ptg}^{+/+}(\mathrm{WT})$ mice after sex-steroid manipulation. (A) Serum adiponectin levels. (B) Serum leptin levels. Control pttg ${ }^{-1}$ males (black bars) had lower adiponectin and leptin levels when compared with age-matched $\mathrm{ptg}^{+/+}$control males (white bars); ${ }^{*} P<0 \cdot 05 ;{ }^{* *} P<0 \cdot 01$. Gonadectomized $\mathrm{pttg}^{-1-}$ males (gray bars) had elevated adiponectin (A) and leptin levels (B) at 8 and 10 months when compared with age-matched control pttg ${ }^{-1-}$ males (black bars); ${ }^{*} P<0 \cdot 05 ;{ }^{* *} P<0 \cdot 01 ;{ }^{* *} P<0 \cdot 001$. Gonadectomized $p^{*} t^{-1-}$ males treated with estradiol (diagonally striped bar) have elevated adiponectin (A) but not leptin (B) levels at 8 months compared with age-matched control pttg $/^{-1-}$ males (black bars); ${ }^{*} P<0 \cdot 05$ ( $n=3-5$ in each group). G, gonadectomy; $\mathrm{P}$, placebo; E2, estradiol.
\end{abstract}

To determine potential mechanisms for the observed enhanced insulin sensitivity, fasted serum adipokine levels were measured ( $n=3-5$ in each group; Fig. 5$)$. pttg $^{-1-}$ males exhibit a gradual decrease in adiponectin and leptin concentrations with age, as compared with $\mathrm{pttg}^{+/+}$males (for adiponectin at 8 months: $4 \cdot 9 \pm 0 \cdot 8$ versus $9 \cdot 4 \pm$ $0.9 \mu \mathrm{g} / \mathrm{ml} \quad(P<0 \cdot 05)$ and at 10 months: $3.9 \pm 1$ versus $9 \cdot 6 \pm 0.9 \mu \mathrm{g} / \mathrm{ml}(P<0 \cdot 01)$; for leptin at 8 months: $1.9 \pm$ 1.4 versus $8.6 \pm 1.5 \mathrm{ng} / \mathrm{ml}(P<0.05)$ and at 10 months: $1 \pm 0.5$ versus $9 \cdot 2 \pm 1.8 \mathrm{ng} / \mathrm{ml}(P<0.01)$ in control $\mathrm{pttg}^{-}$ and $\mathrm{ptg}^{+/+}$respectively; all by one-way ANOVA). Similar observations were made in gonadectomized pttg $^{-1-}$ males treated with DHT, as compared with wild-type counterparts (data not shown). In contrast, gonadectomized pttg $^{-/}$males have elevated levels of both adipokines as compared with age-matched control $\mathrm{pttg}^{-}{ }^{-}$males. Adiponectin at 8 months (Fig. 5A) was $13 \pm 0.8 \mu \mathrm{g} / \mathrm{ml}$ in gonadectomized $\mathrm{pttg}^{-1}$ - versus $4.9 \pm 0.8 \mu \mathrm{g} / \mathrm{ml}$ in control $\mathrm{pttg}^{-\prime-}(P<0.001)$, and at 10 months $15 \pm 1.6 \mu \mathrm{g} / \mathrm{ml}$ in gonadectomized $\mathrm{pttg}^{-1-}$ versus $3 \cdot 9 \pm 1 \mu \mathrm{g} / \mathrm{ml}$ in 
control pttg ${ }^{-1-}(P<0 \cdot 01$; both by one-way ANOVA $)$. Leptin levels at 8 months (Fig. 5B) were $14.3 \pm 5.7 \mathrm{ng} / \mathrm{ml}$ in gonadectomized $\mathrm{pttg}^{-}{ }^{-}$mice versus $1.9 \pm 1.3 \mathrm{ng} / \mathrm{ml}$ in control $\mathrm{pttg}^{-1-}(P<0.05)$, and at 10 months they were $17 \cdot 3 \pm 8 \cdot 4 \mathrm{ng} / \mathrm{ml}$ in gonadectomized $\mathrm{pttg}^{-/}$versus $1 \pm 0.5 \mathrm{ng} / \mathrm{ml}$ in control $\mathrm{pttg}^{-/-}$mice $(P<0 \cdot 01)$. Serum adiponectin but not leptin levels were also elevated in 8-month-old gonadectomized $\mathrm{pttg}^{-1-}$ mice treated with estradiol (Fig 5A; $7.5 \pm 0.6 \mu \mathrm{g} / \mathrm{ml}$ in gonadectomized $\mathrm{pttg}^{-\prime-}$ mice treated with estradiol versus $3.9 \pm 1 \mu \mathrm{g} / \mathrm{ml}$ in control $\mathrm{pttg}^{-/-}$mice; $\left.P<0 \cdot 05\right)$.

\section{Pancreatic $\beta$-cell area is not increased in gonadectomized $\mathrm{pttg}^{-1-}$ males with or without estradiol therapy}

The percentage $\beta$-cell area occupying total pancreatic sections was markedly reduced in $\mathrm{pttg}^{-/-}$control males when compared with $\mathrm{pttg}^{+/+}$controls $(0.08 \pm 0.07$ versus $7 \cdot 9 \pm 2.5 \% ; P<0.001$ by ANOVA and Bonferroni group analysis). Although gonadectomy followed by estradiol or no added therapy increased the percentage $\beta$-cell area in $\mathrm{pttg}^{-1-}$ males $(0 \cdot 27 \pm 0 \cdot 24$ and $0 \cdot 18 \pm 0 \cdot 05$ versus $0.08 \pm 0.07 \%$ respectively) this difference was not significant when assessed by ANOVA and Bonferroni group analysis. The average islet size and the number of islets per $\mu \mathrm{m}^{2}$ was also unaffected by gonadectomy in $\mathrm{pttg}^{-{ }^{-1}}$ males with and without added estradiol therapy, compared with $\mathrm{pttg}^{-/-}$control male mice (data not shown).

\section{Discussion}

In pttg-null mice, sexually dimorphic diabetes is associated with $\beta$-cell hypoplasia, likely a consequence of disrupted securin function. Failure of differentiated islets to proliferate to maturation results in hypoinsulinemia, hyperglycemia and severe lipodistrophy at 6 months of age (Wang et al. 2003). It is unclear why $\beta$-cells are apparently selectively affected by securin deficiency. $\beta$-Cells undergo a proliferation phase before the end of the first postnatal month, when the pancreas is subject to dynamic changes in response to variations in insulin demand. Securin loss and resultant abnormal cell-cycle progression directly affect $\beta$-cell mass expansion, resulting in diabetes. It is likely that loss of fat tissue and reduced body weight are secondary to hypoinsulinemia. pttg $^{-/-}$animals also exhibit selective pituitary, splenic and testicular hypoplasia, with no apparent functional deficits (Wang et al. 2001, 2003).

The results shown here demonstrate that gonadectomy alters the course of diabetes in $\mathrm{pttg}^{-1-}$ males, with four of five males being free of diabetes for up to 13.5 months, and one male animal developing diabetes at 12 months. As a group these gonadectomized males showed glucose intolerance for the first time at 12 months of age. Sexually dimorphic hyperglycemia has been described in several rodent diabetes models in which female sex conferred complete or partial protection from diabetes development (Rossini et al. 1978, Paik et al. 1982, Kava et al. 1989, 1992, Leiter 1989, Efrat 1991, Shi et al. 1994, Kim et al. 2001, Thomas et al. 2001, Weksler-Zangen et al. 2001. Geisler et al. 2002). Several of the models cited demonstrated that male gonadectomy is protective for diabetes development. These include streptozotocin-induced diabetes, in which gonadectomy ameliorated (Rossini et al. 1978) or attenuated (Maclaren et al. 1980) hyperglycemia, the obese Zuker rat (Kava et al. 1992), the Cohen diabetic rat (Weksler-Zangen et al. 2001) and the OLET fatty rat (Shi et al. 1994). In most of these studies, removal of testosterone from the sex-steroid milieu of the male animal improved insulin sensitivity, while in others, like the streptozotocin model, the mechanism for the negative effect of testosterone on blood sugar levels is unclear (Maclaren et al. 1980, Kromann et al. 1982, Paik et al. 1982). The negative effects of testosterone have been shown in a study where neonatal therapy of female rats with testosterone caused fetal imprinting followed by subsequent development of insulin resistance at an older age (Nilsson et al. 1998). In humans male hypogonadism is associated with glucose intolerance, decreased lean body mass and increased fat mass, mostly through alterations in insulin-sensitivity markers (Fukui et al. 2000, Stellato et al. 2000, Oh et al. 2002, Bhasin 2003). Gonadectomy of $\mathrm{pttg}^{-{ }^{-}}$male mice further lowered body weight which might account for protective effects of gonadectomy on diabetes development in pttg-null mice.

In the work shown here, we demonstrate that the delay and attenuation of diabetes development in gonadectomized $\mathrm{pttg}^{-/-}$males was not caused by a consistent rise in insulin levels but rather through a decrease in insulin resistance, as reflected in the ITT and the HOMA-IR index. Insulin sensitivity as assessed by the ITT measures mainly muscle glucose clearance, while insulin sensitivity of fat and liver are not appreciably reflected by this test (Goren et al. 2004). This might explain the lack of a more robust increase in insulin sensitivity in gonadectomized $\mathrm{pttg}^{-/-}$male mice with or without estradiol therapy, as shown by the ITT. Tests directly assessing fat or liver insulin sensitivity may point to greater differences between these groups. For technical reasons, we performed ITT on control mice at 8 months of age and compared results with those of older gonadectomized mice treated with estradiol or placebo. Control $\mathrm{pttg}^{-1-}$ and $\mathrm{pttg}^{+/+}$male mice would have been expected to show more insulin resistance if assayed at an older age, so the finding that gonadectomy increases insulin sensitivity would have likely been magnified, rather than diminished, if the ITT was performed at similar ages.

Increased insulin sensitivity was associated with a dramatic rise in serum adiponectin levels following gonadectomy of both $\mathrm{pttg}^{-1-}$ and $\mathrm{pttg}^{+/+}$males. Adiponectin has been identified as an insulin-sensitizing peptide. Low 
adiponectin levels are a feature of insulin resistance in humans and rodents with insulin resistance, whether accompanied by either lipoatrophy or obesity (Yamauchi et al. 2001, Berg et al. 2002, Haque et al. 2002), and exogenous adiponectin administration reverses insulin resistance in rodents (Haque et al. 2002). In insulinopenic rodent models for diabetes like the non-obese diabetic (NOD) mouse and streptozotocin-induced diabetes, treatment with adiponectin normalized glucose levels, without a rise in insulin (Berg et al. 2001). Given these results, adiponectin is a strong candidate for mediating the observed improvement in diabetes onset in gonadect-

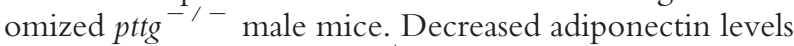
seen in age-matched pttg $^{-1-}$ control male mice when compared with $\mathrm{pttg}^{+/+}$control animals is likely secondary to the pttg-null lipodystrophy, which is caused primarily by the low insulin levels. Several studies in humans and rodents have shown sexual dimorphism in plasma levels of adiponectin, with males having lower levels than females (Berg et al. 2002, Nishizawa et al. 2002). Furthermore, hypogonadal males with low testosterone levels have higher levels of adiponectin when compared with eugonadal males, and testosterone treatment attenuates adiponectin levels (Lanfranco et al. 2004). In rodents, male but not female gonadectomy was followed by increased adiponectin levels and improved insulin sensitivity (Nishizawa et al. 2002). Increased adiponectin levels in females is likely related to the low-testosterone state (Nishizawa et al. 2002).

Serum leptin levels also increased in gonadectomized pttg $^{-/-}$male mice when compared with control pttg $^{-1-}$ males. Leptin, secreted from fat tissue, is a body-weight regulator through its control of feeding and energy expenditure. The association between leptin levels and insulin resistance are not yet fully delineated (Ceddia et al. 2002). The observed increase in serum leptin levels in gonadectomized $\mathrm{pttg}^{-1-}$ males was not as marked as the increased adiponectin levels, and therefore leptin is not a major candidate for diabetes protection in our model.

Compared with gonadectomy alone, estradiol treatment of gonadectomized $\mathrm{pttg}^{-}{ }^{-}$male mice conferred additional protection from diabetes development. These animals had normal fasting blood glucose levels for up to 13.5 months and a normal response to IPGTT for up to 12 months. These changes were accompanied by increased indices of insulin sensitivity and higher levels of adiponectin, but not leptin.

Several studies have shown that estrogen exerts protective effects on male animals with a genetic predisposition to develop diabetes. In $d b / d b$ mice on the C57BL/KsJ background chronic low-dose estradiol therapy effectively ameliorated the severity of diabetes and obesity typical of this model, reduced body mass and restored functional pancreatic islet cytoarchitecture (hypercytolipidemia, cytohypertrophy and atrophy). These changes were accompanied by increased pancreatic and serum insulin levels
(Garris \& Garris 2005). In obese hIAPP (human islet amyloid polypeptide) males, diabetes was prevented when estradiol therapy was started at a young age, and diabetes controlled when estradiol therapy was initiated at an older age. These protective effects were mediated by increased insulin sensitivity secondary to estrogen-induced weight loss. Estradiol therapy in these mice also prevented $\beta$-cell degeneration and amyloid deposition (Geisler et al. 2002).

Estradiol has been shown both in vivo and in vitro to have positive effects on the structure, size, number and function of pancreatic islet $\beta$-cells (Bailey \& Ahmed-Sorour 1980, Puah \& Bailey 1985, Zhu et al. 1998, Choi et al. 2005). Recent evidence supports the presence of a novel non-nuclear estrogen receptor which exerts rapid actions in the endocrine pancreas, enabling calcium fluxes that favor insulin secretion (Ropero et al. 2002, Sutter-Dub 2002). In our experiments serum insulin levels were not increased following gonadectomy and estradiol therapy; moreover, we did not observe beneficial trophic effects of estradiol on islet morphology. The results favor increased insulin sensitivity induced by estradiol in pttg-null mice. Mechanisms by which estradiol conferred almost total protection against diabetes development in $\mathrm{pttg}^{-/-}$males are still undetermined.

Estrogen has a key role in body fat composition. Lack of estrogen, as seen in the postmenopausal state, is characterized by increased body fat and changes in body fat distribution shifting from peripheral to central adiposity concomitant with increased insulin resistance (Gambacciani et al. 2001, Wu et al. 2001, Liu et al. 2004). Male mice lacking estrogen receptors have increased adipose tissue, increased insulin resistance and impaired glucose tolerance (Heine et al. 2000).

The additional protection conferred by estradiol in our model could be due to decreased adipose tissue or its mobilization from central (android) to peripheral (gynoid) depots, which indirectly increases insulin sensitivity. Estradiol treatment in gonadectomized $\mathrm{pttg}^{-/-}$and $\mathrm{pttg}^{+/+}$male mice was accompanied with weight loss (data not shown), most probably through decreased fat mass, but we did not perform quantitative assessment of fat tissue and/or its distribution.

Taken together, the results suggest that gonadectomy with and without estradiol therapy confers diabetes protection in $\mathrm{pttg}^{-/-}$male mice by increased insulin sensitivity associated with increased serum adiponectin levels and elevated leptin levels. Delayed diabetes onset in pttg $^{-1-}$ females may also in part occur secondarily to higher levels of adiponectin and leptin when compared with age-matched pttg $^{-1-}$ control males. Supporting these conclusions is the fact that the percent $\beta$-cell area, average islet size and the number of pancreatic islets per $\mu \mathrm{m}^{2}$ were not increased in $\mathrm{pttg}^{-/-}$males following gonadectomy, either with or without estradiol therapy. This conclusion is also supported by the unaltered fasted or challenged insulin and C-peptide levels following these 
sex-steroid interventions. These results show that, in the absence of pttg, effects of male-selective $\beta$-cell hypoplasia are restored by sex-steroid environmental changes and their effect on peripheral insulin sensitivity.

\section{Acknowledgements}

The authors wish to thank Lihua Xia for her excellent technical assistance.

\section{Funding}

Supported by NIH grant DK064169. The authors declare that there is no conflict of interest that would prejudice the impartiality of this scientific work.

\section{References}

Bailey CJ \& Ahmed-Sorour H 1980 Role of ovarian hormones in the long-term control of glucose homeostasis. Effects of insulin secretion. Diabetologia 19 475-481.

Berg AH, Combs TP, Du X, Brownlee M \& Scherer PE 2001 The adipocyte-secreted protein Acrp30 enhances hepatic insulin action. Nature Medicine 7 947-953.

Berg AH, Combs TP \& Scherer PE 2002 ACRP30/adiponectin: an adipokine regulating glucose and lipid metabolism. Trends in Endocrinology and Metabolism 13 84-89.

Bhasin S 2003 Effects of testosterone administration on fat distribution, insulin sensitivity, and atherosclerosis progression. Clinical Infectious Diseases 37 Suppl 2 S142-S149.

Ceddia RB, Koistinen HA, Zierath JR \& Sweeney G 2002 Analysis of paradoxical observations on the association between leptin and insulin resistance. FASEB Journal 16 1163-1176.

Choi SB, Jang JS \& Park S 2005 Estrogen and exercise may enhance beta-cell function and mass via insulin receptor substrate 2 induction in ovariectomized diabetic rats. Endocrinology 146 4786-4794.

Efrat S 1991 Sexual dimorphism of pancreatic beta-cell degeneration in transgenic mice expressing an insulin-ras hybrid gene. Endocrinology 128 897-901.

Fukui M, Koyama M, Nakagawa Y, Itoh Y, Nakamura N \& Kondo M 2000 Castration and diabetes. Diabetes Care 23 1032-1033.

Gambacciani M, Ciaponi M, Cappagli B, De Simone L, Orlandi R \& Genazzani AR 2001 Prospective evaluation of body weight and body fat distribution in early postmenopausal women with and without hormonal replacement therapy. Maturitas 39 125-132.

Garris DR \& Garris BL 2005 Estrogenic restoration of functional pancreatic islet cytoarchitecture in diabetes $(\mathrm{db} / \mathrm{db})$ mutant C57BL/KsJ mice: relationship to estradiol localization, systemic glycemia, and persistent hyperinsulinemia. Cell Tissue Research 319 231-242.

Geisler JG, Zawalich W, Zawalich K, Lakey JR, Stukenbrok H, Milici AJ \& Soeller WC 2002 Estrogen can prevent or reverse obesity and diabetes in mice expressing human islet amyloid polypeptide. Diabetes 51 2158-2169.

Goren HJ, Kulkarni RN \& Kahn CR 2004 Glucose homeostasis and tissue transcript content of insulin signaling intermediates in four inbred strains of mice: C57BL/6, C57 BLKS/6, DBA/2, and 129X1. Endocrinology 145 3307-3323.

Haque WA, Shimomura I, Matsuzawa Y \& Garg A 2002 Serum adiponectin and leptin levels in patients with lipodystrophies. Journal of Clinical Endocrinology and Metabolism 87 2395-2398.
Heine PA, Taylor JA, Iwamoto GA, Lubahn DB \& Cooke PS 2000 Increased adipose tissue in male and female estrogen receptor-alpha knockout mice. PNAS 97 12729-12734.

Iglesias A, Murga M, Laresgoiti U, Skoudy A, Bernales I, Fullaondo A, Moreno B, Lloreta J, Field SJ, Real FX et al. 2004 Diabetes and exocrine pancreatic insufficiency in E2F1/E2F2 double-mutant mice. Journal of Clinical Investigations 113 1398-1407.

Jones ME, Thorburn AW, Britt KL, Hewitt KN, Wreford NG, Proietto J, Oz OK, Leury BJ, Robertson KM, Yao S et al. 2000 Aromatase-deficient (ArKO) mice have a phenotype of increased adiposity. PNAS 97 12735-12740.

Kava RA, West DB, Lukasik VA \& Greenwood MR 1989 Sexual dimorphism of hyperglycemia and glucose tolerance in Wistar fatty rats. Diabetes 38 159-163.

Kava RA, West DB, Lukasik VA, Wypijewski C, Wojnar Z, Johnson PR \& Greenwood MR 1992 The effects of gonadectomy on glucose tolerance of genetically obese $(\mathrm{fa} / \mathrm{fa})$ rats: influence of sex and genetic background. International Journal of Obesity Related Metabolism Disorders 16 103-111.

Kim JH, Sen S, Avery CS, Simpson E, Chandler P, Nishina PM, Churchill GA \& Naggert JK 2001 Genetic analysis of a new mouse model for non-insulin-dependent diabetes. Genomics 74 273-286.

Kromann H, Christy M, Lernmark A, Nedergaard M \& Nerup J 1982 The low dose streptozotocin murine model of type 1 (insulin-dependent) diabetes mellitus: studies in vivo and in vitro of the modulating effect of sex hormones. Diabetologia 22 194-198.

Lanfranco F, Zitzmann M, Simoni M \& Nieschlag E 2004 Serum adiponectin levels in hypogonadal males: influence of testosterone replacement therapy. Clinical Endocrinology (Oxford) 60 500-507.

Leiter EH 1981 The influence of genetic background on the expression of mutations at the diabetes locus in the mouse IV. Male lethal syndrome in CBA/Lt mice. Diabetes 30 1035-1044.

Leiter EH 1989 The genetics of diabetes susceptibility in mice. FASEB Journal 3 2231-2241.

Leiter EH, Chapman HD \& Coleman DL 1989 The influence of genetic background on the expression of mutations at the diabetes locus in the mouse. V. Interaction between the $\mathrm{db}$ gene and hepatic sex steroid sulfotransferases correlates with genderdependent susceptibility to hyperglycemia. Endocrinology 124 912-922.

Li FX, Zhu JW, Tessem JS, Beilke J, Varella-Garcia M, Jensen J, Hogan CJ \& DeGregori J 2003 The development of diabetes in E2f1/E2f2 mutant mice reveals important roles for bone marrow-derived cells in preventing islet cell loss. PNAS 100 12935-12940.

Liu ML, Xu X, Rang WQ, Li YJ \& Song HP 2004 Influence of ovariectomy and 17 beta-estradiol treatment on insulin sensitivity, lipid metabolism and post-ischemic cardiac function. International Journal of Cardiology 97 485-493.

Maclaren NK, Neufeld M, McLaughlin JV \& Taylor G 1980 Androgen sensitization of streptozotocin-induced diabetes in mice. Diabetes 29 710-716.

Matthews DR, Hosker JP, Rudenski AS, Naylor BA, Treacher DF \& Turner RC 1985 Homeostasis model assessment: insulin resistance and beta-cell function from fasting plasma glucose and insulin concentrations in man. Diabetologia 28 412-419.

Nilsson C, Niklasson M, Eriksson E, Bjorntorp P \& Holmang A 1998 Imprinting of female offspring with testosterone results in insulin resistance and changes in body fat distribution at adult age in rats. Journal of Clinical Investigations 101 74-78.

Nishizawa H, Shimomura I, Kishida K, Maeda N, Kuriyama H, Nagaretani H, Matsuda M, Kondo H, Furuyama N, Kihara S et al. 2002 Androgens decrease plasma adiponectin, an insulin-sensitizing adipocyte-derived protein. Diabetes 51 2734-2741.

Oh JY, Barrett-Connor E, Wedick NM \& Wingard DL 2002 Endogenous sex hormones and the development of type 2 diabetes in older men and women: the Rancho Bernardo study. Diabetes Care 25 55-60. 
Paik SG, Michelis MA, Kim YT \& Shin S 1982 Induction of insulin-dependent diabetes by streptozotocin. Inhibition by estrogens and potentiation by androgens. Diabetes 31 724-729.

Pei L \& Melmed S 1997 Isolation and characterization of a pituitary tumor-transforming gene (PTTG). Molecular Endocrinology 11 433-441.

Puah JA \& Bailey CJ 1985 Insulinotropic effect of ovarian steroid hormones in streptozotocin diabetic female mice. Hormone Metabolism Research 17 216-218.

Ropero AB, Soria B \& Nadal A 2002 A nonclassical estrogen membrane receptor triggers rapid differential actions in the endocrine pancreas. Molecular Endocrinology 16 497-505.

Rossini AA, Williams RM, Appel MC \& Like AA 1978 Sex differences in the multiple-dose streptozotocin model of diabetes. Endocrinology 103 1518-1520.

Saba S, Zhu W, Aronovitz MJ, Estes NA 3rd, Wang PJ, Mendelsohn ME \& Karas RH 2002 Effects of estrogen on cardiac electrophysiology in female mice. Journal of Cardiovascular Electrophysiology 13 276-280.

Shi K, Mizuno A, Sano T, Ishida K \& Shima K 1994 Sexual difference in the incidence of diabetes mellitus in Otsuka-Long-Evans-Tokushima-Fatty rats: effects of castration and sex hormone replacement on its incidence. Metabolism 43 1214-1220.

Stellato RK, Feldman HA, Hamdy O, Horton ES \& McKinlay JB 2000 Testosterone, sex hormone-binding globulin, and the development of type 2 diabetes in middle-aged men: prospective results from the Massachusetts male aging study. Diabetes Care 23 490-494.

Sutter-Dub MT 2002 Rapid non-genomic and genomic responses to progestogens, estrogens, and glucocorticoids in the endocrine pancreatic B cell, the adipocyte and other cell types. Steroids 67 77-93.

Thomas MK, Devon ON, Lee JH, Peter A, Schlosser DA, Tenser MS \& Habener JF 2001 Development of diabetes mellitus in aging transgenic mice following suppression of pancreatic homeoprotein IDX-1. Journal of Clinical Investigations 108 319-329.

Umeda M, Kanda T \& Murakami M 2003 Effects of angiotensin II receptor antagonists on insulin resistance syndrome and leptin in sucrose-fed spontaneously hypertensive rats. Hypertension Research 26 485-492. van Eickels M, Patten RD, Aronovitz MJ, Alsheikh-Ali A, Gostyla K, Celestin F, Grohe C, Mendelsohn ME \& Karas RH 2003 17-beta-estradiol increases cardiac remodeling and mortality in mice with myocardial infarction. Journal of the American College of Cardiology 41 2084-2092.

Wang Z, Yu R \& Melmed S 2001 Mice lacking pituitary tumor transforming gene show testicular and splenic hypoplasia, thymic hyperplasia, thrombocytopenia, aberrant cell cycle progression, and premature centromere division. Molecular Endocrinology 15 1870-1879.

Wang Z, Moro E, Kovacs K, Yu R \& Melmed S 2003 Pituitary tumor transforming gene-null male mice exhibit impaired pancreatic beta cell proliferation and diabetes. PNAS $1003428-3432$.

Weksler-Zangen S, Yagil C, Zangen DH, Ornoy A, Jacob HJ \& Yagil Y 2001 The newly inbred cohen diabetic rat: a nonobese normolipidemic genetic model of diet-induced type 2 diabetes expressing sex differences. Diabetes 50 2521-2529.

Wu SI, Chou P \& Tsai ST 2001 The impact of years since menopause on the development of impaired glucose tolerance. Journal of Clinical Epidemiology 54 117-120.

Yamauchi T, Kamon J, Waki H, Terauchi Y, Kubota N, Hara K, Mori Y, Ide T, Murakami K, Tsuboyama-Kasaoka N et al. 2001 The fat-derived hormone adiponectin reverses insulin resistance associated with both lipoatrophy and obesity. Nature Medicine 7 941-946.

Zhu M, Mizuno A, Kuwajima M, Ogino T, Murakami T, Noma Y, Sano T \& Shima K 1998 Ovarian hormone-induced beta-cell hypertrophy contributes to the homeostatic control of beta-cell mass in OLETF female rat, a model of Type II diabetes. Diabetologia 41 799-805.

Zou H, McGarry TJ, Bernal T \& Kirschner MW 1999 Identification of a vertebrate sister-chromatid separation inhibitor involved in transformation and tumorigenesis. Science 285 418-422.

Received in final form 12 March 2006

Accepted 15 March 2006

Made available online as an Accepted Preprint

31 March 2006 